\title{
BENTUK ISTILAH-ISTILAH \\ UPACARA PANGGIH PERNIKAHAN ADAT JAWA \\ Kajian Etnolinguistik
}

\section{Listi Hanifah, Irma Apriliyani Rahayu, Septian Rinata}

\author{
listihan18@gmail.com \\ Universitas Negeri Semarang
}

\begin{abstract}
The ceremony is an interesting cultural symbol to be studied, especially in terms of language and cultural. This research was conducted to find out the forms of terms that exist Panggih ceremony in Karanganyar Regency. The research method carried out in this study used qualitative research methods. The results of the analysis describing the forms of terms that exist in the Javanese traditional wedding ceremonies are words, phrases, and clauses. The words found are eight words, included in the category of verbs and nouns with lexical meanings for the word monomorphemic, and the grammatical meaning of the word polymorphism. The phrases found are 17 phrases which are divided into lingual categories and units. The phrase in this study can be interpreted grammatically. Finally, the term found is a term in the form of a clause that is included in a free clause.
\end{abstract}

Keywords: Forms of Terms, Ethnolinguistics, Regency of Karanganyar, Advanced Ceremony.

Etnolinguistik merupakan bidang kajian bahasa mengenai bahasa dan budaya. Etnolinguistik merupakan bidang kajian yang bersifat interdisipliner, yakni mengenai bahasa dan budaya. Istilah etnolinguistik berasal dari kata "etnologi" dan "linguistik", yang lahir karena adanya penggabungan antara pendekatan yang biasa dilakukan oleh para ahli etnologi (kini: antropologibudaya) dengan pendekatan linguistik (Ahimsa, 1997). Etnolinguistik dapat disebut juga dengan antropolinguistik atau linguistik antropologi. Penamaan ini didasarkan pada fokus kajian etnolinguistik yang berupa bahasa. jika fokus kajiannya adalah budaya, maka dapat disebut dengan antropologi linguistik.

Pelaksanaan upacara pernikahan adat jawa memiliki beberapa tata cara atau urutan yang masing-masing memiliki makna budaya tersendiri. Menurut Hawkins 
(2012) budaya adalah suatu kompleks yang meliputi pengetahuan, keyakinan, seni, moral, adat-istiadat serta kemampuan dan kebiasaan lain yang dimiliki manusia sebagai bagian masyarakat. Ciri khas yang dimiliki oleh sebuah budaya yang tumbuh berkembang di masyarakat memiliki nilai-nilai kearifan lokal yang patut dilestarikan. Ketersediaan informasi terkait pengetahuan aspek nilai budaya dalam upacara adat jawa begitu terbatas. Hal ini, tidak didukung juga adanya buku bacaan yang dapat digunakan untuk pembaca umum supaya tetap memahami ajaran dari makna budaya yang ada di dalamnya.

Penelitian ini dilakukan guna mengetahui bentuk istilah-istilah yang ada dalam upacara Panggih yang berada di Kabupaten Karanganyar. Lokasi ini dipilih karena jarak yang dekat dari Kota Surakarta yang sudah banyak menjadi lokasi penelitian sebelumnya. Peneliti ingin mengetahui bentuk istilah-istilah dalam upacara panggih pernikahan adat Jawa yang dilakukan di Kabupaten Karanganyar yang kemudian dibuatkan sebuah ensiklopedia supaya dapat diketahui oleh khalayak.

Bentuk istilah-istilah yang dimaksud ialah kata, frasa, dan klausa yang khas dalam tata cara upacara Panggih. Istilah adalah perkataan yang khusus mengandung arti yang tertentu di lingkungan sesuatu ilmu pengetahuan, pekerjaan atau kesenian (Poerwadarminto, 1982: 388). Istilah (term) menurut Kridalaksana (2001) adalah kata atau gabungan kata yang dengan cermat mengungkapkan konsep, proses, keadaan, atau sifat yang khas dalam bidang tertentu. Menurut Koentjaraningrat (2002: 26) istilah diartikan sebagai keseluruhan dari isi serta kemampuan alam pikiran dan alam jiwa manusia dalam hal menanggapi lingkungannya. Lingkungan yang dimaksud dalam hal ini adalah lingkungan di mana kita tinggal. Berkaitan dengan penelitian ini, peneliti menyimpulkan bahwa istilah adalah penyebutan atau penamaan terhadap sesuatu yang berkaitan dengan kebudayaan dengan maksud tertentu. Istilah yang dimaksud adalah istilah-istilah yang ada dalam upacara Panggih pernikahan adat Jawa. Oleh karena itu rumusan permasalahan yang dimunculkan dalam penelitian ini adalah menganalisis bentuk dan makna leksikal dalam upacara Panggih di Kabupaten Karanganyar. 
Listi Hanifah, Irma Apriliyani Rahayu, Septian Rinata, Bentuk Istilah-Istilah

Upacara Panggih Pernikahan Adat Jawa: Kajian Etnolinguistik

\section{METODE PENELITIAN}

Pendekatan yang digunakan dalam penelitian ini yaitu pendekatan metodologis dan pendekatan teoretis. Pendekatan metodologis dalam penelitian ini adalah metode deskriptif kualitatif. Pendekatan deskriptif digunakan untuk menganalisis data yang berupa leksikon, sehingga menghasilkan hasil analisis berupa gambaran bentuk leksikon, makna leksikal, dan makna kultural. Dalam penelitian ini secara teoretis menggunakan pendekatan etnolinguistik.

Data adalah istilah-istilah berupa kata, frasa, dan klausa yang diduga mengandung unsur-unsur yang digunakan dalam upacara adat Jawa. Sumber data yang digunakan dalam penelitian ini adalah tuturan yang diperoleh dari dukun pengantin, pranata cara dalam prosesi Upacara Panggih dan orang tua yang dipercaya untuk menjadi penasihat atau mengarahkan dalam pernikahan. Selain informan tersebut, peneliti juga menggunakan referensi data berupa video prosesi Upacara Panggih dalam adat pernikahan Jawa dan referensi pustaka.

Metode yang digunakan adalah metode simak. Metode simak adalah metode yang dilakukan dengan cara menyimak tuturan-tuturan yang diduga mengandung tuturan yang dibutuhkan. Teknik dasar yang digunakan adalah teknik sadap. Kemudian, teknik lanjutan yang digunakan adalah teknik simak libat cakap, teknik simak bebas libat cakap, teknik rekam, dan teknik catat (Sudaryanto, 2015). Kemudian, metode cakap digunakan dalam pengumpulan data. Metode cakap adalah metode yang dilakukan dengan adanya kontak antara peneliti dan penutur yang menjadi informan. Teknik lanjutan yang digunakan ialah teknik rekam dan teknik catat.

Analisis data menggunakan metode padan dan metode agih milik Sudaryanto. Teknik dalam metode padan yang digunakan oleh peneliti dalam penelitian ini adalah teknik dasar yaitu teknik pilah unsur penentu dengan daya pilah referensial. Daya pilah referen yang dimaksud berupa simbol dan tuturan pranata cara dalam prosesi 
upacara Panggih. Metode agih adalah salah satu metode untuk menganalisis data di samping metode padan. Menurut Sudaryanto (2015:18), alat penentu dalam metode agih adalah bagian dari bahasa yang bersngkutan. Dalam penelitian ini, peneliti juga menggunakan metode agih dalam menganalisis data. Teknik yang digunakan adalah teknik Bagi Unsur Langsung (BUL). Peneliti membagi satuan lingual data yang didapat menjadi beberapa bagian atau unsur yang langsung membentuk satuan lingual yang dimaksud.

Metode penyajian analisis data menggunakan metode deskriptif formal dan informal. Metode diskriptif merupakan metode yang semata-mata hanya berdasarkan pada fakta-fakta yang ada atau fenomena secara empiris hidup pada penuturpenuturnya (Sudaryanto, 2015). Metode informal yaitu metode penyajian hasil analisis data yang menggunakan kata-kata yang sederhana agar mudah dipahami. Analisis informal dalam penelitian ini agar dapat mempermudah pemahaman terhadap setiap hasil penelitian. Metode formal yaitu metode penelitian data dengan menggunakan dokumen tentang data yang dipergunakan sebagai lampiran.

\section{HASIL DAN PEMBAHASAN}

Dalam penelitian ini, peneliti menganalisis istilah-istilah dalam upacara Panggih pernikahan adat Jawa. Istilah-istilah yang dianalisis dalam penelitian ini berjumlah 26 istilah menggunakan kajian etnolinguistik. Peneliti menganalisis bentuk dan makna istilah-istilah yang ada dalam upacara Panggih pernikahan adat Jawa di Kabupaten Karanganyar. Makna istilah yang dianalisis adalah makna leksikal dan gramatikal dari istilah-istilah tersebut. Analisis data dapat diuraikan sebagai berikut:

\section{Kata}

Dalam penelitian ini, peneliti menemukan 8 kata sebagai istilah-istilah dalam upacara Panggih pernikahan adat Jawa. Kedelapan kata tersebut dapat diklasifikasikan dalam bentuk verba dan nomina sebagai berikut: 
Listi Hanifah, Irma Apriliyani Rahayu, Septian Rinata, Bentuk Istilah-Istilah

Upacara Panggih Pernikahan Adat Jawa: Kajian Etnolinguistik

\section{Verba}

Verba menurut Kurniati $(2017,41)$ merupakan jenis kata yang menunjukkan tindakan atau perbuatan suatu benda atau makhluk. Verba terbagi menjadi verba murni dan verba nonmurni. Verba murni merupakan verba yang berasal dari verba, sedangkan verba nonmurni merupakan verba yang sudah mengalami proses transposisi. Dalam penelitian ini, verba yang ditemukan adalah sebagai berikut.

a. Titahing [titahen]

Titahing termasuk dalam kata yang merupakan kata kerja atau verba. Kata titahing merupakan kata kerja polimorfemis yang terdiri dari dua morfem dengan proses morfologis berupa penambahan sufiks. Kata ini berasal dari morfem $\{$ titah $\}+$ \{-ing $->$ [titahing], yang memiliki arti 'perintah'.

b. Kaapit [kaapIt]

Kata kaapit merupakan verba yang secara perilaku mengandung makna leksikal keadaan. Kata kaapit merupakan kata kerja polimorfemis. Kata kaapit tersusun atas morfem $\{k a\}$ dan morfem \{apit\} sehingga menjadi kaapit yang memiliki makna diapit atau didampingi.

c. Panggih [pangIh]

Panggih merupakan kata yang memiliki kelas verba. Kata panggih tidak mengalami proses morfologis apapun karena merupakan kata kerja monomorfemis. Panggih dalam bahasa Indonesia dapat diartikan dengan bertemu.

d. Tumapak [tumapa?]

Kata tumapak merupakan kata yang termasuk dalam kategori verba. Kata tumapak merupakan kata kerja polimorfemis. Kata ini berasal dari kata \{tapak\} yang 
sudah mengalami proses morfologis berupa sisipan \{-um-], sehingga menjadi [tumapak].

\section{Nomina}

Nomina menurut Kurniati (2017: 26) adalah suatu jenis kata yang menandai atau menamai suatu benda yang dapat berdiri sendiri dalam kalimat dan tidak bergantung pada jenis kata lain, seperti orang, tempat, benda, kualitas, tindakan. Dalam penelitian ini, nomina yang ditemukan ialah:

a. Antiga [antigo]

Antiga merupakan kata benda atau nomina yang memiliki arti 'telur'. Kata antiga merupakan kata benda polimorfemis karena terdiri dari dua morfem penyusun. Kata antiga mengalami proses morfologis berupa afiks $\{\mathrm{aN}-\}+\{$ tigan $\}->$ [antiga].

b. Bongkoan [boyko'an]

Kata bongkoan merupakan nomina polimorfemis yang mengalami proses morfologis berupa penambahan sufiks $\{-$ an $\}$. Kata bongkoan dalam pernikahan adat jawa memiliki pengertian seserahan.

c. Pinanganten [pinayanten]

Kata pinanganten merupakan kata yang masuk ke dalam kelas nomina. Kata pinanganten merupakan nomina polimorfemis berasal dari kata penganten kemudian diberi sisipan $\{$-ing- $\}$, sehingga menjadi pinanganten.

\section{d. Sesepuh $[\mathrm{s} \partial \mathrm{s} \partial \mathrm{pUh}]$}

Istilah sesepuh merupakan nomina polimorfemis yang mendapat proses morfologis berupa reduplikasi sebagian di awal kaga. Kata sesepuh berasal dari kata sepuh yang memiliki arti yang 'dituakan'. 
Listi Hanifah, Irma Apriliyani Rahayu, Septian Rinata, Bentuk Istilah-Istilah Upacara Panggih Pernikahan Adat Jawa: Kajian Etnolinguistik

\section{Frasa}

Frasa merupakan satuan gramatikal yang terdiri dari dua kata atau lebih yang tidak melampaui batas fungsi unsur klausa (Ramlan dalam Kurniati, 2008: 27). Frasa dapat diklasifikasikan berdasarkan beberapa hal, yaitu berdasarkan distribusinya, berdasarkan kategorinya, berdasarkan satuan lingual unsur-unsur penyusunnya, dan berdasarkan kategori unsur-unsurnya. Dalam penelitian ini, peneliti menganalisis frasa berdasarkan kategori dan berdasarkan satuan lingual unsur-unsur penyusunnya. Dalam penelitian ini peneliti menemukan 18 istilah yang masuk dalam kategori frasa, yaitu:

a. Ahli madya

Ahli madya merupakan frasa nominal. Disebut frasa nominal karena terdiri dari dua kata yang merupakan nomina. Frasa ini memiliki makna anak tengah.

b. Pisang sanggan

Pisang sanggan termasuk dalam kategori frasa nomina karena terdiri dari dua kata yang masuk dalam kelas nomina. Frasa pisang sanggan merupakan salah satu jenis pisang yang ada di Jawa.

c. Tumangkepin pisang raja

Tumangkeping pisang raja merupakan frasa yang terdiri dari tiga kata. Frasa ini berstruktur kata frasa, yaitu kata tumangkeping dan frasa pisang raja. Kata tumangkeping sendiri merupakan kata yang telah mengalami proses morfologis yang jika digambarkan menjadi $\{$ tangkep $\}+\{$-um $\} \rightarrow\{$ tumangkep $\}+\{$-ing $\} \rightarrow$ [tumangkeping]. 
d. Pasrah bongkoan

Pasrah bongkoan merupakan frasa verbal karena terdiri dari akta pasrah yang masuk dalam kategori kata kerja atau verba, serta kata bongkoan yang masuk dalam kategori kata benda atau nomina.

Kata pasrah tidak mengalami proses morfologis apapun. Kata pasrah memiliki arti menyerahkan. Kata bongkoan merupakan nomina yang mengalami proses morfologis berupa penambahan sufiks $\{-\mathrm{an}\}$. Kata bongkoan dalam pernikahan adat jawa memiliki pengertian seserahan.

e. Widadari sapta cacahe

Widadari sapta cacahe termasuk dalam kategori frasa numeralial. Kata widadari memiliki pengertian bidadari. Dalam frasa tersebut, terkandung pengertian bahwa bidadari yang berjumlah tujuh.

\section{f. Pinanganten kakung}

Pinanganten kakung termasuk dalam frasa nominal karena terdiri dari dua kata yang keduanya merupakan nomina. Kata pinanganten merupakan kata yang masuk ke dalam kelas nomina. Kata pinanganten berasal dari kata penganten kemudian diberi sisipan $\{$-ing- $\}$, sehingga menjadi pinanganten. Di samping itu, kata kakung yang tidak mengalami proses morfologis apapun memiliki arti laki-laki.

\section{g. Ambalang suruh}

Ambalang suruh merupakan frasa verbal. Dikatakan frasa verbal karena kata penyusun frasa tersebut terdiri dari kata kerja (verba) dan kata benda (nomina). Kata ambalang merupakan verba yang tersusun dari morfem $\{\mathrm{aN}-\}+\{$ balang $\}->$ [ambalang] yang memiliki arti 'melempar'. Kata 'suruh' di sini tidak mengalami proses morfologis apapun. Kata suruh memiliki arti daun sirih. 
Listi Hanifah, Irma Apriliyani Rahayu, Septian Rinata, Bentuk Istilah-Istilah Upacara Panggih Pernikahan Adat Jawa: Kajian Etnolinguistik

h. Jawat asto

Jawat asta merupakan frasa verbal karena terdiri dari verba dan nomina. Kata jawat sebagai verba memiliki pengertian jabat atau menjabat, sedangkan kata asta dalam bahasa Indonesia memiliki arti 'tangan'. Oleh karena itu, kata jawat asta memiliki pengertian jabat tangan.

i. Wewengkoning tiyang sepuh

Wewengkoning tiyang sepuh merupakan frasa verbal yang terdiri dari kata wewengkoning sebagai verba pasif dan tiyang sepuh sebagai frasa nomina.

Kata wewengkoning merupakan kata polimorfemis karena terdiri dari beberapa morfem. Bentuk dasarnya adalah wengku yang langsung mendapat sufiks $\{$-an $\}$ sehingga menjadi wengkon. Selanjutnya, kata wengkon mengalami reduplikasi sebagian di depan kata, menjadi wewengkon. Setelah itu, kata wewengkon mendapat sufiks $\{$-ing $\}$ sehingga menjadi wewengkoning yang memiliki makna 'dikelilingi'.

Frasa tiyang sepuh merupakan frasa nomina yang seluruh penyusunnya merupakan nomina. Makna dari frasa ini adalah 'orang yang dituakan' atau 'orang tua'.

j. Ambasuh samparan

Ambasuh samparan termasuk dalam frasaverbal karena terdiri dari kata ambasuh sebagai verba dan kata samparan sebagai nomina. Kata ambasuh sudah mengalami proses morfologis berupa imbuhan afiks $\{\mathrm{aN}-\}$ sehingga memiliki arti membasuh, sedangkan kata samparan tidak mengalami proses morfologis apapun dan memiliki arti 'kaki'. 
k. Junjung drajat

Junjung drajat merupakan frasa verbal yang terdiri dari kata junjung sebagai verbal dan kata drajat merupakan nomina. Kedua kata dalam frasa ini tidak mengalami proses morfologis apapun. Secara gramatikal, frasa ini dapat diartikan 'mengangkat derajat'.

1. Tirto wening

Tirto wening tergolong dalam frasa adjektiva karena tersusun dari kata tirta yang masuk dalam kategori kata benda (nomina) dan kata wening yang masuk dalam kategori kata sifat (adjektiva). Kata tirta memiliki arti 'air', dan kata wening memiliki arti 'bening'.

m. Kendhi pertolo

Kendhi pertala merupakan frasa nomina yang terdiri dari dua kata, yaitu kata kendhi dan kata pertala. Kedua kata penyusun frasa ini merupakan kata dalam kelas nomina.

Kata kendhi dalam bahasa Jawa biasa diartikan sebagai wadah untuk menyimpan air, sedangkan kata pertala memiliki arti tanah. Maka jika diartikan secara gramatikal menjadi wadah penyimpanan air yang tebuat dari tanah.

n. Sindur binayang

Sindur binayang merupakan frasa verbal yang terdiri dari kata sindur sebagai nomina dan kata binayang sebagai verba. Kata sindur merupakan kata monomorfemis karena hanya terdiri dari satu morfem. Kata sindur memiliki makna 'merah muda'. Kata binayang merupakan kata polimorfemis karena terdiri dari dua morfem, yaitu morfem \{bayang\} dan morfem $\{-$ in- $\}$ sebagai sisipan. Jika digambarkan, maka menjadi $\{$ bayang $\}+\{$-in- $\}->$ [binayang]. Kata binayang memiliki makna terbayang- 
Listi Hanifah, Irma Apriliyani Rahayu, Septian Rinata, Bentuk Istilah-Istilah Upacara Panggih Pernikahan Adat Jawa: Kajian Etnolinguistik

bayang. Jika dimaknai secara gramatikal menjadi merah muda yang terbayangbayang.

o. Putra sarimbit

Putra sarimbit merupakan frasa numeralial yang terdiri dari kata putra sebagai nomina dan kata sarimbit sebagai numeralia. Kata putra dan sarimbit merupakan kata monomorfemis karena hanya terdiri dari satu morfem. Putra sarimbit memiliki makna 'putra sepasang'.

p. Pangkon timbang

Pangkon timbang merupakan frasa verbal yang terdiri dari kata pangkon sebagai verba yang memiliki arti memangku, dan juga kata timbang sebagai verba yang memiliki arti menimbang. Secara keseluruhan, maka artinya adalah menimbang dengan cara memangku.

q. Sego punar

Sego punar merupakan frasa yang termasuk dalam kategori frasa adverbial. Kata sego dalam bahasa Indonesia memiliki arti 'nasi' tergolong dalam kelas nomina, dan kata punar memiliki arti 'kuning' tergolong dalam kelas adverbia. Secara harfiah, frasa sego kuning memiliki arti nasi kuning.

\section{Klausa}

Klausa menurut Ramlan adalah satuan gramatik yang terdiri dari unsur subjek, predikat baik disertai objek, pelengkap, dan keterangan ataupun tidak disertai (Kurniati, 2008: 45). Dalam penelitian ini, peneliti hanya menemukan satu istilah yang masuk dalam kategori klausa. Istilah tersebut adalah istilah ngangkarya jagad. Analisis dari istilah tersebut adalah, 
Ngangkarya jagad merupakan klausa bebas yang sudah memiliki informasi lengkap meskipun dalam klausa ini subjeknya dilesapkan. Klausa ini terdiri dari kata ngangkarya predikat dan jagad sebagai objek. Ngangkarya merupakan verba yang masuk dalam jenis verba transitif, yang teerdiri dari morfem $\{\mathrm{N}-\}+\{$ karya $\} \rightarrow$ ngangkarya, memiliki arti 'membuat'.Jagad merupakan nomina yang tidak mengalami proses morfologis apapun. Kata jagad dapat diartikan dengan 'alam semesta'. Jika digabungkan, maka ngangkarya jagad memiliki pengertian 'membuat alam semesta'.

\section{SIMPULAN}

Dari penelitian ini, peneliti menyimpulkan bahwa bentuk istilah yang ada dalam upacara panggih pernikahan adat Jawa adalah kata, frasa, dan klausa. Kata yang ditemukan berjumlah 8 kata, termasuk dalam kategori verba maupun nomina dengan makna leksikal bagi kata monomorfemis, serta makna gramatikal bagi kata polimorfemis. Frasa yang ditemukan berjumlah 17 frasa yang terbagi berdasarkan kategori dan satuan lingual unsur penyusunnya. Frasa dalam penelitian ini dapat dimaknai secara gramatikal. Terakhir, istilah yang ditemukan adalah istilah berbentuk klausa yang termasuk dalam klausa bebas.

\section{DAFTAR PUSTAKA}

Ahimsa-Putra, H.S. (1997). "Etnolinguistik : Beberapa Bentuk Kajian”. Makalah Temu Ilmiah Bahasa dan Sastra. Yogyakarta: Departemen Pendidikan dan Kebudayaan, Pusat Pembinaan dan Pengembangan Bahasa, Balai Penelitian Bahasa.

Dewa I, P.w \& Rohmadi, M. (2008). Semantik Teori dan Analisis. Surakarta: Yuma Pustaka.

Hawkins, Peter. (2012). Creating a Coaching Culture. New York: Bell and Bain Ltd. Irmawati, Waryunah. (2013). Makna Simbolik Upacara Siraman Pengantin Adat Jawa.Walisongo. no. 2. Vol. 21. Hal 309.

Koentjaraningrat.(2002). Pengantar Ilmu Antropologi. PT. Rineka Cipta, Jakarta Kridalaksana, Harimurti. (2008). Kamus Linguistik. Jakarta: PT Gramedia Pustaka. Kuncoro, Setyo Nur. (2014). Tradisi Upacara Perkawinan Adat Keraton Surakarta (Studi Pandangan Ulama Dan Masyarakat Kauman, Pasar Kliwon. Surakarta. 
Listi Hanifah, Irma Apriliyani Rahayu, Septian Rinata, Bentuk Istilah-Istilah

Upacara Panggih Pernikahan Adat Jawa: Kajian Etnolinguistik

Skripsi. Jurusan Al-Ahwal Al-Syakhshiyyah, Fakultas Syariah, Universitas Islam Negeri Maulana Malik Ibrahim Malang.

Kurniati, Endang. (2017). Morfologi Lanjut Bahasa Jawa. Bahan Ajar. Semarang: Universitas Negeri Semarang.

Kurniati, endang. (2008). Sintaksis Bahasa Jawa. Semarang: Griya Jawi.

Miles, Matthew B dan A. Michael Huberman. (1992). Analisis Data Kualitatif. Terjemahan Tjetjep Rohendi Rohidi. Jakarta: Universitas Indonesia.

Murtiadji,Sri Supadmi. (1993). Tata Rias Pengantin Gaya Yogyakarta.Yogyakarta: Gramedia Pustaka Utama.

Octaviana, Frisca. (2014). Implementasi Makna Simbolik Prosesi Pernikahan Adat Jawa Tengah pada Pasangan Suami Istri. Naskah Publikasi. Surakarta: Universitas Muhammadiyah Surakarta.

Poerwadarminta. (1982). Kamus Besar Bahasa Indonesia. Jakarta : Balai Pustaka.

Prasetyono, Dwi Sunar. (2003). Tata Cara Paes lan Pranatacara Gagrag Ngayogyakarta. Yogyakarta: Absolut.

Pratiknyo, Ananto. (2009). Istilah-Istilah Upacara Perkawinan Adat Jawa Bubak Kawah Dan Tumplak Punjen Di Kecamatan Bendosari Kabupaten Sukoharjo (Suatu Kajian Etnolinguistik). Surakarta: Universitas Sebelas Maret.

Santoso, Joko. (2006). Semantik. Yogyakarta: FBS UNY.

Sasangka, Sry S. (2008). Paramasastra Gaggrag Anyar Bahasa Jawa. Jakarta: Citra Jaya Murti.

Sudaryanto. (2015). Metode dan Aneka Teknik Analisis Bahasa. Yogyakarta: Sanata Dharma University Press.

Sulasman dan Gumilar. (2013). Teori-Teori Kebudayaan (dari Teori Hingga Aplikasi). Bandung: CV Pustaka Setia.

Sumarji, Nanang. (2013). Panyandra Upacara Panggih Pengantin Adat Jawa di Kabupaten Kebumen (Tinjauan Semantik Budaya). Skripsi. Jurusan Bahasa dan Sastra Jawa, Fakultas Bahasa dan Seni. Universitas Negeri Semarang. 